\title{
Stability enhancement of wind energy integrated hybrid system with the help of static synchronous compensator and symbiosis organisms search algorithm
}

\author{
Pabitra Kumar Guchhait and Abhik Banerjee* (D)
}

\begin{abstract}
Conventional proportional integral derivative (PID) controllers are being used in the industries for control purposes. It is very simple in design and low in cost but it has less capability to minimize the low frequency noises of the systems. Therefore, in this study, a low pass filter has been introduced with the derivative input of the PID controller to minimize the noises and to improve the transient stability of the system. This paper focuses upon the stability improvement of a wind-diesel hybrid power system model (HPSM) using a static synchronous compensator (STATCOM) along with a secondary PID controller with derivative filter (PIDF). Under any load disturbances, the reactive power mismatch occurs in the HPSM that affects the system transient stability. STATCOM with PIDF controller is used to provide reactive power support and to improve stability of the HPSM. The controller parameters are also optimized by using soft computing technique for performance improvement. This paper proposes the effectiveness of symbiosis organisms search algorithm for optimization purpose. Binary coded genetic algorithm and gravitational search algorithm are used for the sake of comparison.
\end{abstract}

Keywords: Binary coded genetic algorithm, Gravitational search algorithm, Hybrid power system model, PID controller with derivative filter, Static synchronous compensator, Symbiosis organisms search algorithm, Transient stability

\section{Introduction}

Power system stability draws more attention due to some major problems in modern power system network. The stability of a power system network is broadly categorized into three types, such as, (a) rotor angle stability, (b) frequency stability and (c) voltage stability [1].

The stability belongs to the first category is generally happened in power system for a few seconds under short or transient disturbances. Small signal stability is one kind of angular stability and it is related to the low frequency oscillations of the system [2]. The second kind of instability occurs mainly due to disparity of active power

\footnotetext{
* Correspondence: abhik@nitap.ac.in

Department of Electrical Engineering, National Institute of Technology, Yupia, Arunachal Pradesh, India
}

\section{Springer Open}

in the power system networks. It may lead to serious problem in the network which could be overcome by automatic generation control (AGC) [3]. Another major stability problem that may arise in the power system network is voltage instability. This type of instability occurs in the network due to reactive power imbalance caused by some kinds of disturbances in the system [4]. The focus of this paper renders on control of the reactive power profile for maintaining voltage stability of a hybrid power system model (HPSM).

The distributed generation (DG) is the new road map for small power generation. DG catches attention of the researchers for fulfilling the load demand during peak hours (see [5]). In this case, renewable energy sources play vital roles for its cost effectiveness and reliability (c) The Author(s). 2020 Open Access This article is licensed under a Creative Commons Attribution 4.0 International License, which permits use, sharing, adaptation, distribution and reproduction in any medium or format, as long as you give appropriate credit to the original author(s) and the source, provide a link to the Creative Commons licence, and indicate if changes were made. The images or other third party material in this article are included in the article's Creative Commons licence, unless indicated otherwise in a credit line to the material. If material is not included in the article's Creative Commons licence and your intended use is not permitted by statutory regulation or exceeds the permitted use, you will need to obtain permission directly from the copyright holder. To view a copy of this licence, visit http://creativecommons.org/licenses/by/4.0/. 
[6-8]. Hybrid generating system has come to the consideration for it combines renewable energy sources with non-renewable energy sources to provide centralized electric power to the local areas [6]. Owing to variable nature of the wind and the solar energy sources, these are used widely in DG system. In this paper, wind power is considered as renewable whereas diesel engine has been considered as non-renewable energy source. In the HPSM, irregular behavior of the renewable energy source turns instability which, in turn, causes major problems. To overcome this problem and to improve the performance of the HPSM, various controlling approaches have been applied in the literature. A static VAR controller (SVC) has been employed in the isolated HPSM (refer [9]) to control its reactive power and performance of the model has been analyzed by the use of different kinds of SVC controllers such as SVC type 1, SVC type 2 and SVC type 3.

A SVC-PID control strategy has been successfully reported in the recent state-of-the-art literature in the context of operation of a wind-diesel based HPSM. Values of various parameters of the PID and the SVC controller are selected in [10] by employing seeker optimization algorithm (SOA). Static synchronous compensator (STATCOM) type flexible AC transmission systems (FACTS) devices draw more attention of the researchers for their reactive as well as active power control capabilities as compared to the SVC controller (refer [11]). A few works (such as [12-15]) were reported where STATCOM controller has been adopted to optimize the reactive power and to control the stability of the HPSM. A proportional-integral (PI) controller is applied as secondary controller along with STATCOM or other FACTS devices to minimize other stability problems of the HPSM.

However, this controller does not provide appropriate results for fluctuating nature of the wind energy power generation. To control the HPSM efficiently and to damp out any unpredicted oscillations, this paper presents an intelligent use of proportional integral derivative (PID) controller with derivative filter (PIDF) as a secondary controller along with a STATCOM controller to fulfill the requisite reactive power demand at the time of any disturbance.

For better performance of the renewable based HPSM and fast reactive power control, different soft computing techniques have been applied successfully in the stateof-the-art literatures to tune the various parameters of the controllers. Some of these techniques (such as artificial neural network (ANN) [14], particle swarm optimization (PSO) [15], genetic algorithm (GA) [15], SOA [16]) have proven fruitful when applied to a winddiesel based HPSM to optimize its various controlling parameters.
Cheng and Prayogo [17] have presented symbiosis organisms search (SOS) algorithm in the literature for solving constrained optimization problems.

The tentative findings of this paper are mentioned below.

a) A new control strategy has been applied for the stability improvement of the considered wind-diesel based HPSM and stability improvement capability under small disturbances are being highlighted.

b) Various controller parameters are optimized by various heuristic algorithm techniques and the comparative results are presented and discussed.

c) Performance in terms of stability improvement is presented while comparing the same with the previous ones for the same wind-diesel based HPSM.

The rest of the paper is organized as follows: The next section describes the adopted methodologies. Mathematical problem of the present work is formulated in Section 3. The detail description of the proposed algorithm (i.e., SOS) is given in Section 4. The obtained results are presented and analyzed in Section 5 while the paper is concluded in Section 6 followed by appendix and declaration of the authors in Sections 7-8, in order.

\section{Methods}

The presented work has been carried out in MATLABSIMULINK.

\subsection{Modeling of HPSM under study}

The studied wind-diesel based power system has been depicted in Fig. 1. Intermittent nature of wind energy makes the HPSM highly unbalanced in nature. Under any electrical disturbed conditions (such as sudden changes in load condition or severe kinds of faults), reactive power imbalance takes place which, in turn, may cause serious problems in the transient and the dynamic stability of the system. Under this condition, the frameworks for reactive power demand or its supply by various components of the power system are given below:

In one hand, the reactive power demand by the wind engine based induction generator (IG) running under constant slip $(s)$ is as in (1) (see [9]).

$$
\Delta Q_{I G}=K_{1} \Delta V(s)
$$

On the contrary, the reactive power supply by the diesel engine based synchronous generator (SG) (see [9]) is given in (2).

$$
\Delta Q_{S G}(s)=K_{2} \Delta E_{q}(s)+K_{3} \Delta V(s)
$$

In (2), the term $\Delta E_{q}(s)$ may be written as in (3). 


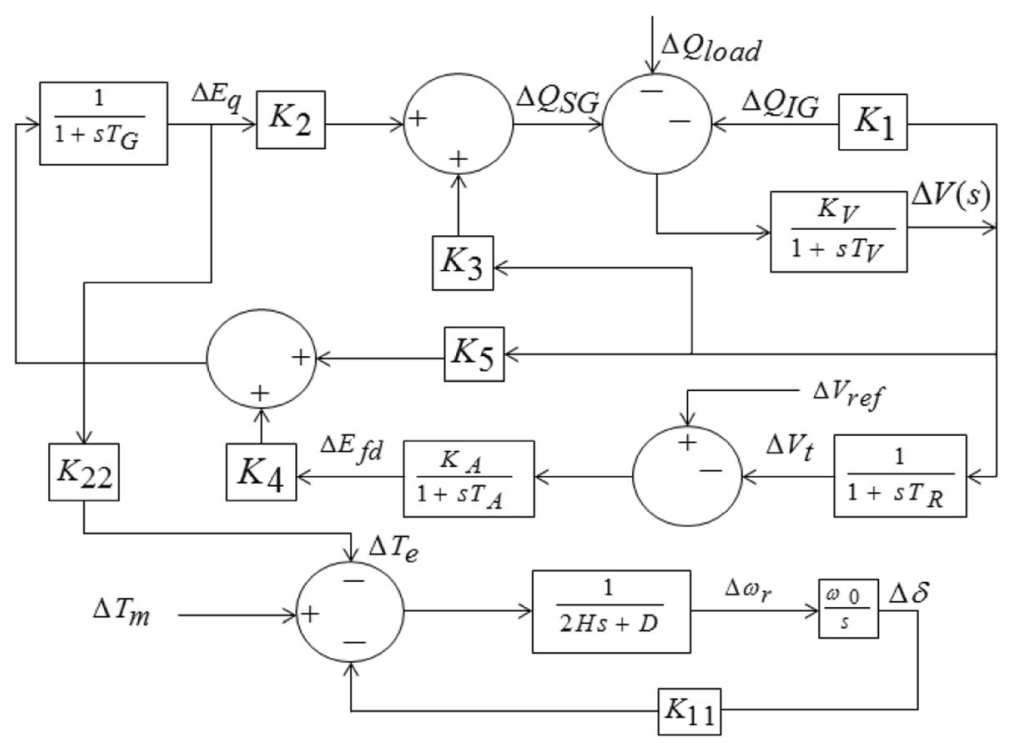

Fig. 1 Wind-diesel based studied power system model

$$
\Delta E_{q}(s)=\left(\frac{1}{1+s T_{G}}\right)\left[K_{4} \Delta E_{f d}(s)+K_{5} \Delta V(s)\right]
$$

Other various parameters related to (1)-(3) are described in Appendix Section.

Under unbalanced condition, the reactive power demands by the components such as load and IG is not completely fulfilled by the SG only. Therefore, to balance the reactive power and to maintain the stability of the HPSM, a FACTs based controller (STATCOM based PIDF controller) has been introduced. The design of the applied controller is presented in next sub-section.

\subsection{Design of the proposed controller}

The amount of requisite reactive power may be fulfilled by a STATCOM controller. The studied STATCOM based PIDF controller has been incorporated in Fig. 2. The reactive power supply by the STATCOM controller [14] may be written in the form (4).

$$
\Delta Q_{c o m}(s)=G_{1} \Delta \alpha(s)+G_{2} \Delta V(s)
$$

The ranges of different STATCOM-PIDF controller (refer Fig. 2) parameters, that should be optimized by different evolutionary algorithms, are depicted here such as, $0.001 \leq K_{p} \leq 100,1 \leq K_{i} \leq 100,0.001 \leq K_{d} \leq 40,0.001 \leq$ $N \leq 1,0.001 \leq T \leq 30,0.001 \leq T_{c} \leq 1.5$ and $0.001 \leq T_{d} \leq 1$.

The other constant values of the different parameters of the studied HPSM are given in the Appendix Section.

\subsection{State space modeling of the proposed HPSM}

The state space model of the complex dynamic linear system may be represented as in (5).

$$
\frac{d \bar{X}}{d t}=A X+B U
$$

Here, $A$ and $B$ are the system state square matrix and the control matrix, respectively. The various parameters of $[A]$ matrix are given in the Appendix Section.

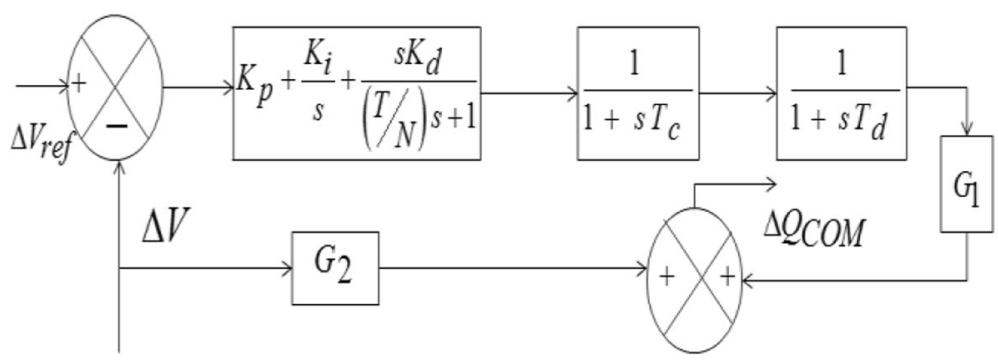

Fig. 2 Proposed STATCOM-PIDF controller model 


\section{Mathematical problem formulations}

\subsection{Fitness function based optimal analysis}

To find out the optimal design of the controller associated with the studied HPSM, a fitness function $(J)$ is defined in (6) (in line with [18]).

$$
\begin{aligned}
\text { fitness function }(J)= & 10 * J_{1}+10 * J_{2}+0.01 * J_{3} \\
& +J_{4}
\end{aligned}
$$

The system performance should be improved by minimizing the $J$ value and it should be achieved by minimizing the overshoot $\left(M_{p}\right)$, increasing the damping of the HPSM. To minimize the fitness function and enhance the relative degree of stability, the controller parameters are optimized by using various soft computing techniques.

In (6), the terms $J_{1}, J_{2}, J_{3}$ and $J_{4}$ replicate the weighting factors and these are connected with the eigenvalues of the studied HPSM. The first term (i.e. $J_{1}$, pertaining to the real portion of eigenvalues of the HPSM) is responsible for the relative stability of the system. The second term, $J_{2}$ depends on the damping ratio. By appropriate opting this weighting factor, the maximum overshoot of the HPSM can be lessened. The third factor (i.e., $J_{3}$ ) is used in the fitness function to boost up the damping of HPSM. The last factor, $J_{4}$ is taken as an arbitrary high value. While choosing appropriate weighting factors during the process of optimization, the value of $J$ should be minimized [10].

The changes in $V_{t}$ may be achieved by minimizing setting time $\left(t_{s}\right)$, steady state error $\left(E_{s s}\right)$, overshoot $\left(M_{p}\right)$ and rising time $\left(t_{r}\right)$. A figure of demerit (FOD) [19] is designed with all these parameters as defined in (7).

$$
F O D=\left(1-e^{-\beta}\right)\left(M_{p}+E_{s s}\right)+e^{-\beta}\left(t_{s}-t_{r}\right)
$$

Here, the term $\beta$ is chosen as 1.0 to reduce the overshoot and steady state error. If $\beta$ is considered lesser than 0.7 , than it reduces rise time and settling time [20].

\subsection{Performance indices parameters}

Another approach to check the system transient stability has been considered in this work. Various performance indices like IAE, IATE, ISE and ITSE are defined, in order, in (8)-(11).

$$
\begin{aligned}
& I A E=\int_{0}^{\infty}\left|e_{t}(t)\right| d t \\
& I A T E=\int_{0}^{\infty} t\left|e_{t}\right| d t
\end{aligned}
$$

$$
\begin{aligned}
& I S E=\int_{0}^{\infty} e_{t}^{2}(t) d t \\
& I T S E=\int_{0}^{\infty} t e_{t}^{2} d t
\end{aligned}
$$

\section{SOS algorithm}

\subsection{Literature survey of the algorithm}

The SOS algorithm was developed by Cheng and Prayogo in 2014 taking the concept from various natures inspired existing methodologies [17]. It is a metaheuristic search algorithm like binary coded genetic algorithm (BGA) [21], ant lion optimization (ALO) [22] and many others. SOS algorithm is used to solve many engineering optimization problems mainly in power system for its excellent control characteristics [23]. There is no control parameter in SOS algorithm to tune. So, the execution time of this algorithm is much less than the others.

\subsection{Basic theory of the SOS algorithm}

Symbiosis means interaction between the living organisms in the ecosystem. This algorithm basically works on three basic steps taking the concept of interactions of the living organisms in the nature and these steps are mutualism, commensalism and parasitism. In mutualism step, the organisms are taking part in their interaction process and, after their interaction, both the organisms get their advantage and, therefore, enhances their fitness value in order to survive for longer time in the ecosystem. In the next step (i.e., commensalism), one of the organism in the interacting organisms enhances its fitness value but the other is almost unchanged. In the last step of interactions (that means in the parasitism of interactions), one organism between the interacting organisms destroys the other and gets its benefit from the ecosystem and also makes its position to the ecosystem. Taking the concepts of these three interaction processes from the ecosystem, SOS algorithm has been developed.

The various equations of these three processes are given chronologically below:

For mutualism, if $M_{i}$ and $M_{j}$ are the two interacting organisms, then after their interactions, the new $M_{i}$ and $M_{j}$ will be as in (12) and (13), in order.

$$
\begin{aligned}
& M_{\text {inew }}=M_{i}+\operatorname{rand}(0,1) *\left(\mathrm{M}_{\text {best }}-M V * \text { benefit factor } 1\right) \\
& M_{\text {jnew }}=M_{j}+\operatorname{rand}(0,1) *\left(M_{\text {best }}-M V * \text { benefitfactor } 2\right)
\end{aligned}
$$

In these two equations, the term $M V$ is known as the mutual vector which constitutes the mutual relations between two the organisms $M_{i}$ and $M_{j}$ and is defined in (14). 


$$
M V=\frac{M_{i}+M_{j}}{2}
$$

Here, in (12)-(13), rand $(0,1)$ represents any random numbers which varies between 0 and 1 and $M_{\text {best }}$ describes the maximum degree of adaptation. The values of benefitfactor 1 and benefit factor 2 are either 1 or 2 . If the organism gets full benefit from their interactions, then it is 2 , otherwise, for any partial benefit, it will be 1 (see [23]).

For commensalism, the new fitness value of the benefitted organisms (i.e., $M_{i}$ and $M_{j}$ ) may be written as in (15).

$$
M_{\text {jnew }}=M_{j}+\operatorname{rand}(-1,1) *\left(M_{\text {best }}-M_{i}\right)
$$

Here, $\left(M_{\text {best }}-M_{i}\right)$ represents the gain of fitness in $M_{j}$ provided by $M_{i}$ that helps $M_{j}$ to survive long time in the ecosystem.

In last phase, two organisms (i.e., $M_{i}$ and $M_{j}$ ) participate in their interaction process. Firstly, $M_{i}$ creates its own vector, namely, parasite-vector. If fitness of parasite-vector, $M_{i}$ is greater than $M_{j}$, then it fully destroys the $M_{j}$ and increases the fitness of parasite-vector. On the contrary, $M_{j}$ destroys $M_{i}$ and increases its fitness.

\subsection{Algorithm flowchart}

The flowchart of SOS algorithm is given in Fig. 3.

\section{Simulation results and discussions}

To establish the present work, simulation of the winddiesel based HPSM has been done in MATLABSIMULINK. The terminal voltage responses are noted by applying a small perturbation of 0.01 p.u. in reference voltage $\left(\Delta V_{\text {ref }}\right)$ or in mechanical torque $\left(\Delta T_{m}\right)$ or in both for the HPSM.

The results are produced under change in load voltage and equivalent reactance. Further, the results have been compared to different techniques. For the studied model, simulation run time is considered for $10 \mathrm{~s}$, number of population is 60 and the number of iteration is 500 . These parameters are taken as common for all the chosen algorithms. Other associated parameters of the chosen algorithms and their considered values are described in Appendix Section.

For the studied case (i.e., model along with a STAT COM-PIDF controller), various optimizing parameters are $K_{p}, K_{i} K_{d} N, T, T_{c}$ and $T_{d}$.

First of all, the results are discussed on the basis of obtained convergence graph of fitness value. This fitness value mobility profile of the studied model is given in Fig. 4. It may be observed from the fitness function mobility graph (i.e., Fig. 4) that the SOS based approach provides better result than the GSA and the BGA based techniques. Table 1 gives the optimizing parameters of the HPSM and its convergence value under different loading conditions. It is also observed from this table that the convergence value is less in every loading condition for the SOS based technique than the others.

\subsection{Transient voltage analysis of the HPSM \\ 5.1.1 Stability analysis under normal loading condition}

The transient stability curve and its performance for different algorithms have been discussed in this subsection. Both under constant loading condition and after the load disturbance of 0.01 p.u. The transient stability has been checked with voltage as given in Fig. 5 . The transient voltage attains its steady state faster for the applied SOS technique. It may be concluded from Fig. 5 that the SOS based optimization technique has better capability to minimize the settling time, overshoot and damping of power system oscillations than the other algorithmic technique. The FOD values are also given in Table 2 and it may be stated that the FOD values for each loading conditions are lower one for the SOS based technique. This can be achieved by minimizing rise time, peak overshoot, settling time and steady state error. Table 2 also includes these values and it may be seen that all the parameters are minimum for the SOS based technique as compared with BGA and GSA based algorithms.

\subsubsection{Stability analysis under increasing or decreasing step load variation}

Figure 6 describes the controller performances while injecting a continuous changing load profile. The transient curve shown in Fig. 7 is mostly having a flat type profile. From this figure it may be concluded that the reactive power mismatch under this stated load disturbance is truly fulfilled.

\subsubsection{Stability impact assessment under different controller structure}

\section{a) Comparison with only model structure}

In this section, the stability issues have been addressed under two test cases (i.e., without controller and with STATCOM-PIDF controller). The obtained transient stability profiles are given in Fig. 8 for the SOS technique. The results in the given figure shows that, for all the applied algorithms, the capability of stability improvement has been increased by applying STAT COM-PIDF controller in the model. With the help of this controller, the response almost goes its steady state at approximately $0.85 \mathrm{~s}$, and $1.09 \mathrm{~s}$ for without controller. From this observation, it may be inferred that the stability issues of the wind-diesel HPSM may be overcome in 


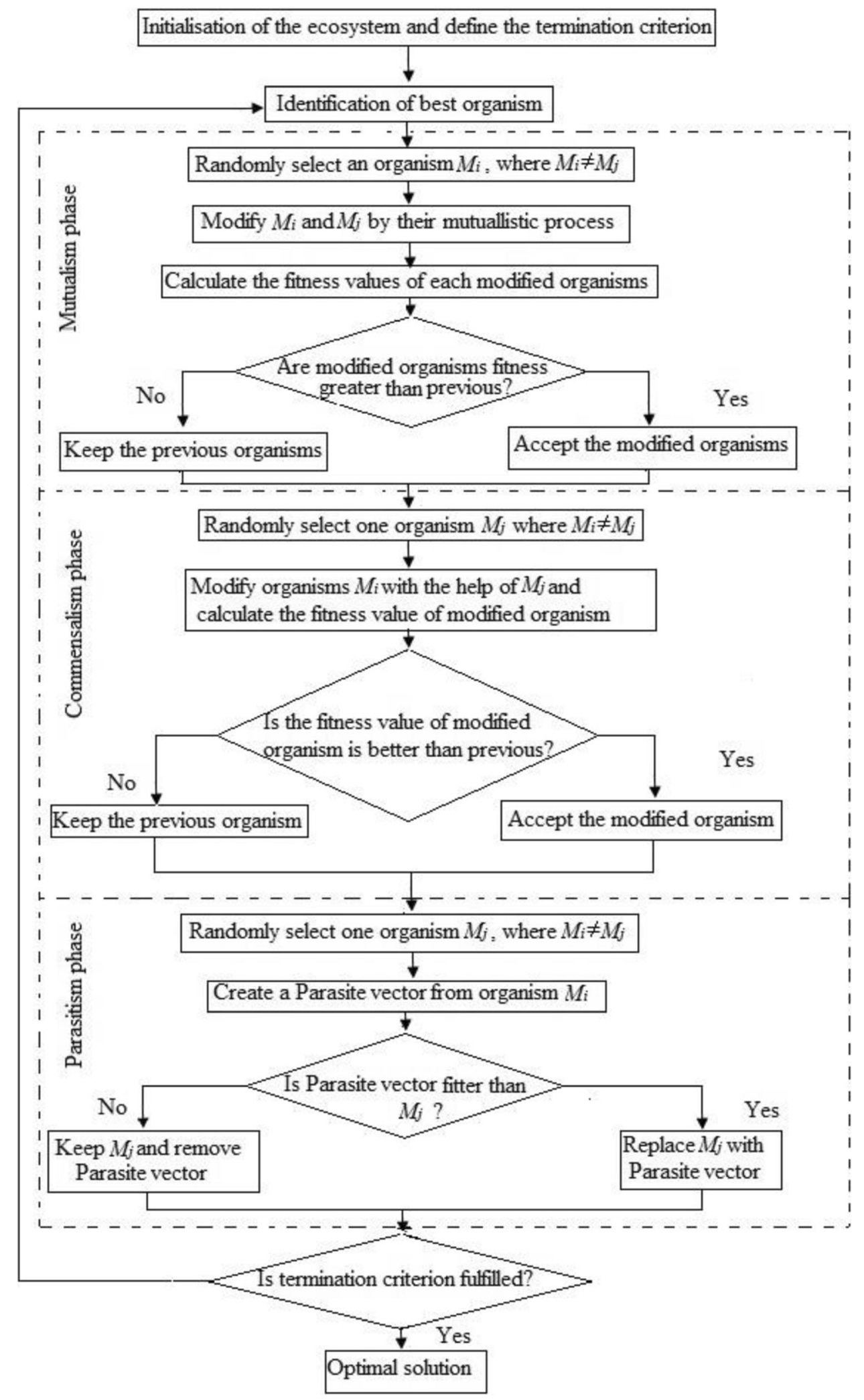

Fig. 3 Flowchart of the SOS algorithm 


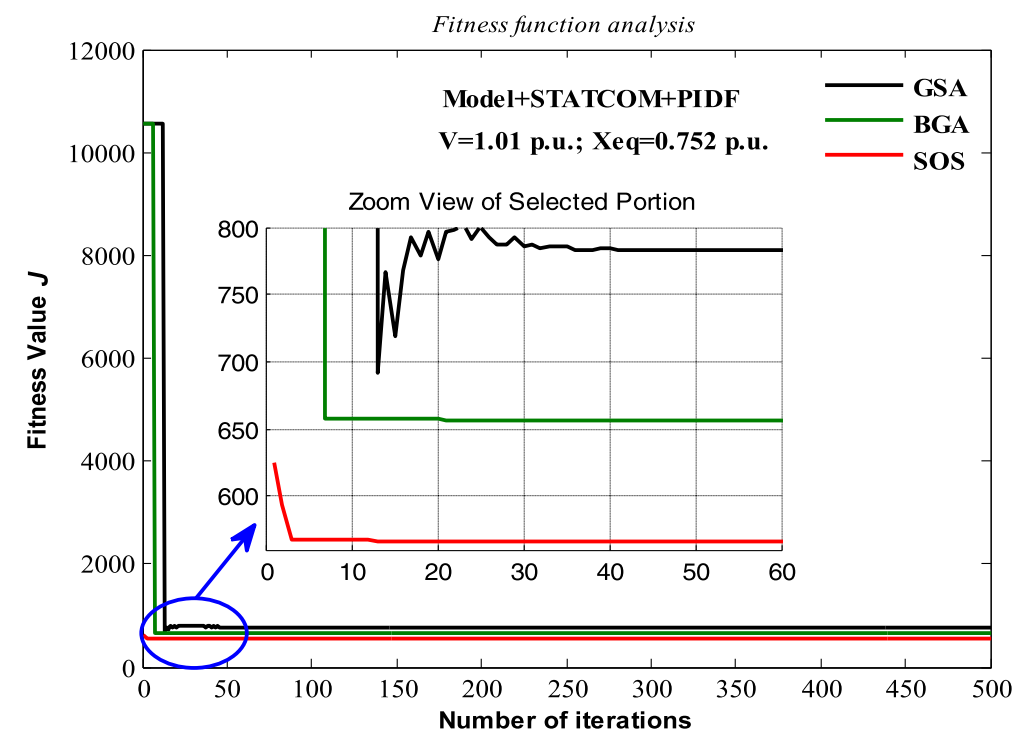

Fig. 4 Convergence profile of the fitness function ( $)$ under $V=1.01$ p.u. and $X e q=0.752$ p.u

Table 1 Optimal controller parameter values and convergence values under different algorithms and input conditions

\begin{tabular}{|c|c|c|c|c|c|c|c|c|c|}
\hline \multirow{2}{*}{$\frac{\text { Input conditions }}{0.97,0.4752}$} & \multirow{2}{*}{$\begin{array}{l}\text { Applied algorithms } \\
\text { GSA }\end{array}$} & \multicolumn{7}{|c|}{ Optimal parameters $\left(K_{p}, K_{i}, K_{d,}, N, T, T_{c}\right.$ and $\left.T_{d}\right)$} & \multirow{2}{*}{$\frac{\text { Fitness value }}{10,567}$} \\
\hline & & 3.4994 & 4.0611 & 28.9541 & 0.5440 & 0.0010 & 0.9337 & 0.0010 & \\
\hline & BGA & 99.6484 & 88.3984 & 13.5156 & 1.2207 & 0.6596 & 99.6529 & 0.0050 & 656.8861 \\
\hline & sos & 0.0010 & 1.0000 & 0.0010 & 0.0256 & 0.0010 & 0.0032 & 0.0010 & 566.4984 \\
\hline \multirow[t]{3}{*}{$0.97,1.08$} & GSA & 3.6868 & 7.6381 & 13.3414 & 0.2605 & 0.0010 & 0.9587 & 0.0010 & 10,567 \\
\hline & BGA & 99.6484 & 88.3984 & 44.1016 & 1.9221 & 1.3766 & 99.6529 & 0.0050 & 656.8784 \\
\hline & sos & 0.0010 & 1.0000 & 0.0010 & 0.0010 & 0.0010 & 0.3665 & 0.0775 & 566.4984 \\
\hline \multirow[t]{3}{*}{$0.99,1.08$} & GSA & 5.6881 & 5.9764 & 14.7117 & 0.0045 & 0.0709 & 0.8912 & 0.0010 & 10,568 \\
\hline & BGA & 99.6484 & 99.6484 & 32.5000 & 1.2363 & 1.3688 & 99.6534 & 0.0050 & 656.8323 \\
\hline & sos & 0.0010 & 1.0000 & 0.0010 & 0.0010 & 0.0017 & 0.0466 & 0.0058 & 566.4984 \\
\hline \multirow[t]{3}{*}{$1.0,0.93$} & GSA & 3.2616 & 3.9840 & 31.4257 & 0.0010 & 0.4622 & 0.9228 & 0.0010 & 673.9469 \\
\hline & $B G A$ & 99.6484 & 94.0234 & 32.8516 & 1.5013 & 1.2519 & 99.6532 & 0.0050 & 656.6698 \\
\hline & sos & 0.0010 & 4.8426 & 0.0010 & 0.0010 & 0.0010 & 0.0065 & 0.0010 & 566.4984 \\
\hline \multirow[t]{3}{*}{$1.0,1.08$} & GSA & 7.2108 & 8.1683 & 22.7107 & 0.4192 & 0.0010 & 0.9856 & 0.0010 & 674.3396 \\
\hline & $B G A$ & 99.6484 & 99.6484 & 43.7500 & 1.9221 & 1.1895 & 99.6534 & 0.0050 & 656.7532 \\
\hline & sos & 0.0010 & 1.0000 & 0.0010 & 0.0017 & 0.0010 & 0.0794 & 0.0094 & 566.4984 \\
\hline \multirow[t]{3}{*}{$1.01,0.752$} & GSA & 0.0010 & 1.1428 & 3.2945 & 0.9497 & 0.1482 & 0.0010 & 26.6038 & 782.2997 \\
\hline & BGA & 99.6484 & 99.6484 & 32.5000 & 1.5013 & 1.1272 & 99.6534 & 0.0050 & 656.7778 \\
\hline & sos & 0.0010 & 3.9871 & 0.0010 & 0.0010 & 0.0010 & 0.3827 & 0.0584 & 566.4984 \\
\hline \multirow[t]{3}{*}{$1.01,0.97$} & GSA & 2.6124 & 7.3855 & 10.2151 & 0.0801 & 0.0026 & 0.7518 & 0.0010 & 671.2094 \\
\hline & BGA & 99.6484 & 94.0234 & 32.8516 & 1.5013 & 1.2519 & 99.6532 & 0.0054 & 656.8762 \\
\hline & sos & 0.0010 & 1.0000 & 0.0010 & 0.0010 & 0.0010 & 0.1047 & 0.0223 & 566.4984 \\
\hline \multirow[t]{3}{*}{$1.01,1.08$} & GSA & 0.0010 & 1.0000 & 27.2641 & 0.7052 & 0.0876 & 0.0010 & 19.1757 & 664.9852 \\
\hline & BGA & 99.6484 & 99.6484 & 62.3828 & 1.8753 & 1.7506 & 99.6534 & 0.0050 & 656.8446 \\
\hline & sos & 0.0010 & 1.0000 & 0.0010 & 0.0010 & 0.0137 & 0.0827 & 0.0200 & 566.4984 \\
\hline
\end{tabular}




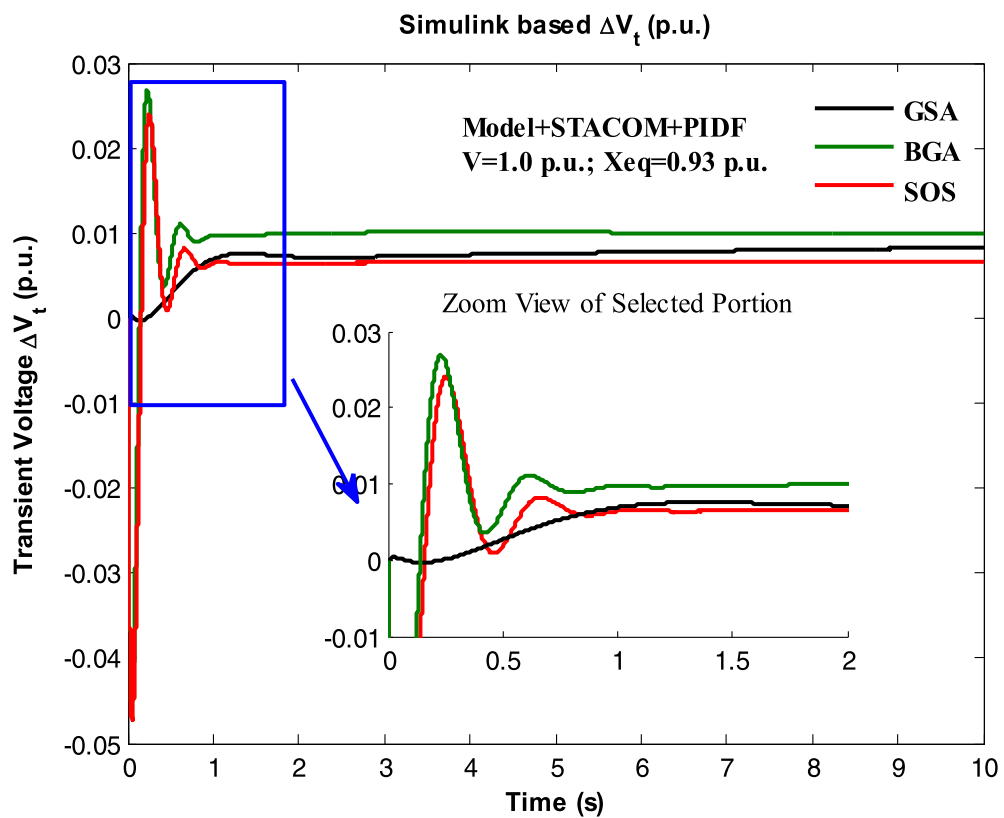

Fig. 5 Transient voltage profiles under a particular load variation ( $V=1.0$ p.u. and Xeq $=0.93$ p.u)

a better way for the considered STATCOM-PIDF based controller.

b) Comparison with different applied FACTS controller

For better control of reactive power and enhancement of stability in wind-diesel HPSM, different FACTs devices are applied in $[14,16,24]$. All the controllers are considered here for the sake of comparison. Figure 9 represents the comparative results with the considered controller structure and it has been observed that the transient voltage is tremendously improved by the use of STATCOM-PIDF controller than the others under any small disturbances.

\subsection{Efficacy test of SOS algorithm}

Different kinds of heuristic optimization techniques have been taken into consideration in previous literatures for stability improvement of the wind-diesel based HPSM. In $[14,20,24]$, oppositional harmony search (OHS),
OGSA and BGA optimization techniques are applied to find out the optimal results of the HPSM. SOS algorithm is also tested for this purpose as it has multiple advantages over the others [17]. For the considered fitness function $(\lambda)$, the applied algorithms (i.e., OGSA, OHS, BGA and SOS) are converged with 801.2365, 712.3274, 656.8323 and 566.4984 respectively, for the input disturbance of $V=0.99$ p.u. and $X e q=1.08$ p.u. The optimal performance for this algorithm is better than the previously employed optimization techniques adopted for this purposes (see Fig. 10). It may be concluded that this algorithm may be considered for the stability improvement of the wind-diesel HPSM as its gives the near global optimal results.

\subsection{Performance indices based analysis}

The calculated values of various predefined performance indices (see (8)-(11)) under different test conditions are given in Table 3. It would be fascinating to note that the SOS produces better values of performance indices as compared to BGA and GSA counterparts. From these

Table 2 Transient voltage parameters under different algorithms and load disturbances

\begin{tabular}{|c|c|c|c|c|c|c|}
\hline Input conditions & Applied algorithms & Peak time $(t p)$ & Rise time (tr) & Steady state error (Ess) & Overshoot $(\mathrm{Mp})$ & FOD \\
\hline \multirow[t]{3}{*}{$V=0.97$, Xeq $=1.08$} & GSA & 10.000 & 9.9971 & 0.0104 & 0.0259 & -0.8795 \\
\hline & $B G A$ & 0.2340 & 0.1849 & 0.0104 & 0.0259 & 1.3257 \\
\hline & sos & 0.2500 & 0.1968 & 0.0065 & 0.0266 & 1.3206 \\
\hline \multirow[t]{3}{*}{$V=1.0$, Xeq $=0.93$} & GSA & 10.0000 & 9.9974 & 0.0078 & 0.0083 & -0.8795 \\
\hline & BGA & 0.2344 & 0.1858 & 0.0100 & 0.0269 & 1.3260 \\
\hline & sos & 0.2548 & 0.2016 & 0.0066 & 0.0240 & 1.3175 \\
\hline
\end{tabular}




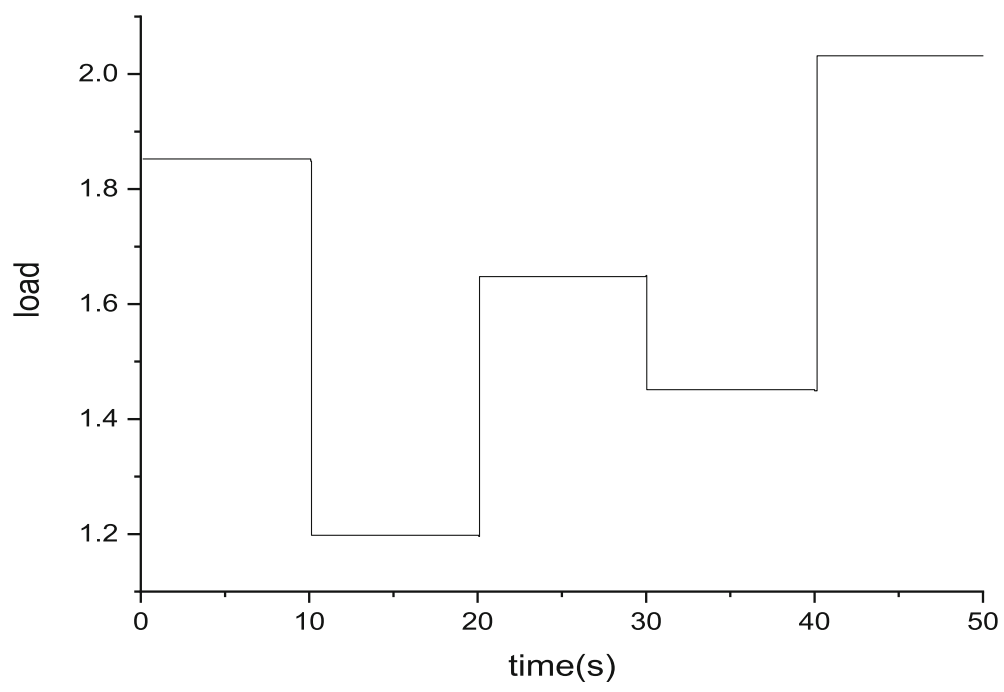

Fig. 6 Variable step load disturbance

results, it is understood that the error in the voltage profile is minimized for the SOS based technique which, in turn, improves the stability of the HPSM.

\section{Conclusions and scope of future work}

In this paper, a new reactive power control strategy has been tested under predefined load profiles. Based on the simulation results, it may be concluded that the STAT COM-PIDF controller has properly managed an appropriate reactive power compensation for the system as per its requirement. Using this controller, the reactive power oscillations have been also minimized. The reactive power problems are overcome for this adopted power system model. From this paper, it is also seen that the transient stability of the system has been improved by using a novel SOS algorithm. It is also observed from the results that the use of SOS algorithm, as an optimization algorithm, yields better results than the other prevailing techniques in terms of convergence characteristics and stability improvement. Thus, SOS may be adopted by the future researchers as an optimizing tool for some other real time optimization processes. The present work is ended while considering linear model. However, a nonlinear system configuration of the studied hybrid wind-diesel based hybrid power system may be an interesting direction for the future researchers.

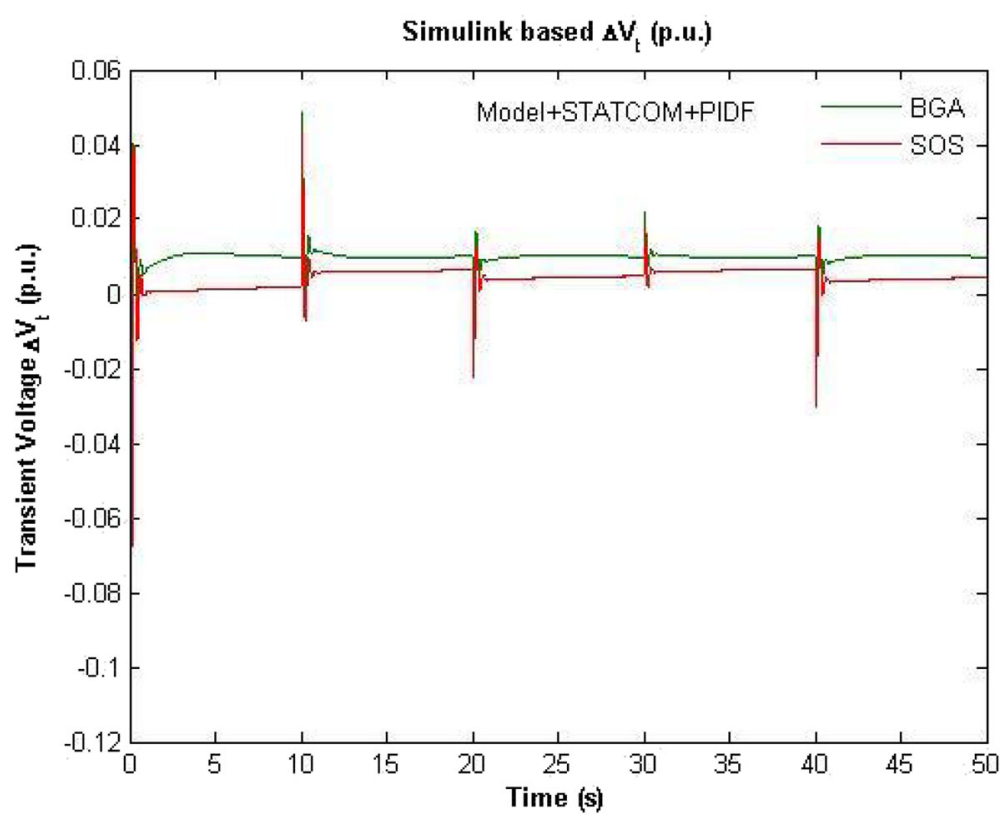

Fig. 7 Transient voltage graph under $V=1.0$ p.u. and $X e q=0.93$ p.u. in presence of variable load 


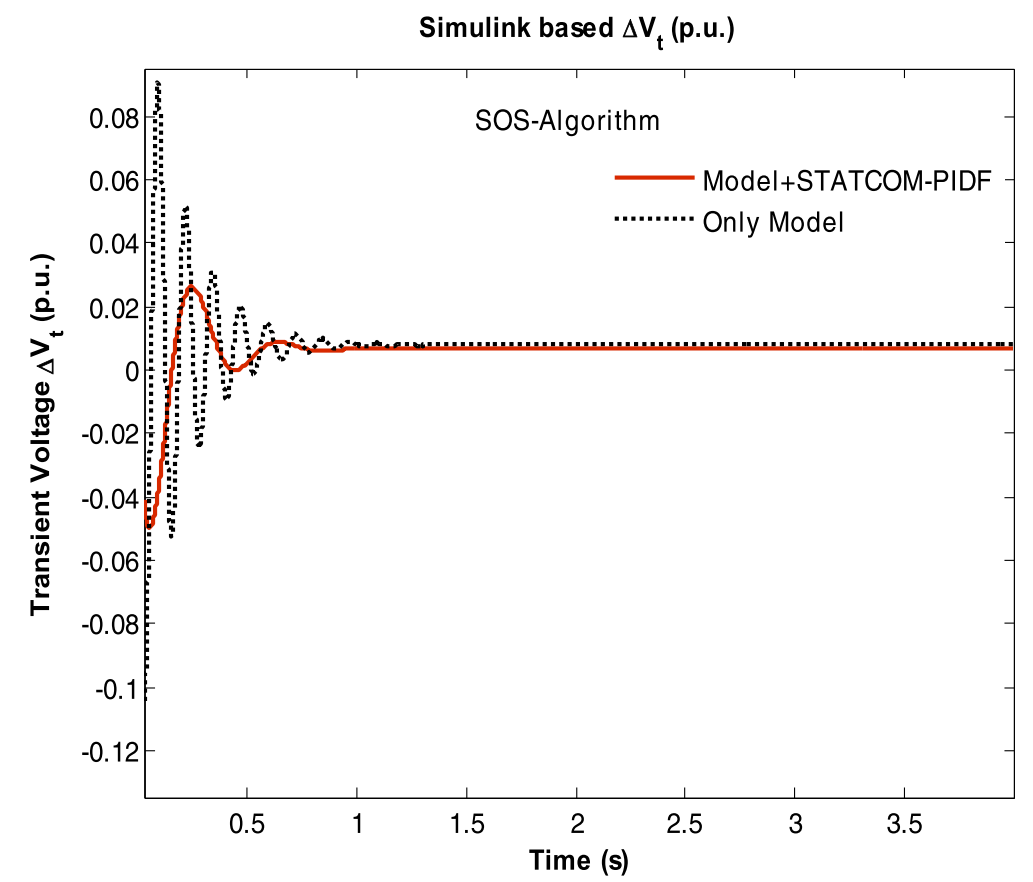

Fig. 8 Comparison of transient voltage response of the HPSM with and without controller for $V=0.99$ p.u. and Xeq $=1.08$ p.u

\section{Nomenclature}

$\Delta P_{I G}, \Delta Q_{I G}$ Change in active and reactive power in the IG, respectively, p.u.

$\Delta P_{S G}, \Delta Q_{S G}$ Change in active and reactive power in the $\mathrm{SG}$, respectively, p.u.

$\Delta P_{\text {load }}, \Delta Q_{\text {load }}$ Change in active and reactive power in load, respectively, p.u.
$\Delta Q_{\text {com }}$ Change in reactive power of the STATCOM controller, p.u.

$\Delta E_{q}, \Delta E_{f d}$ Incremental change in armature emf under steady state and exciter voltage, respectively, p.u.

$\Delta V_{\text {ref }}, \Delta V$ and $\Delta V_{t}$ Incremental change in reference voltage, load voltage and terminal voltage, respectively, p.u.

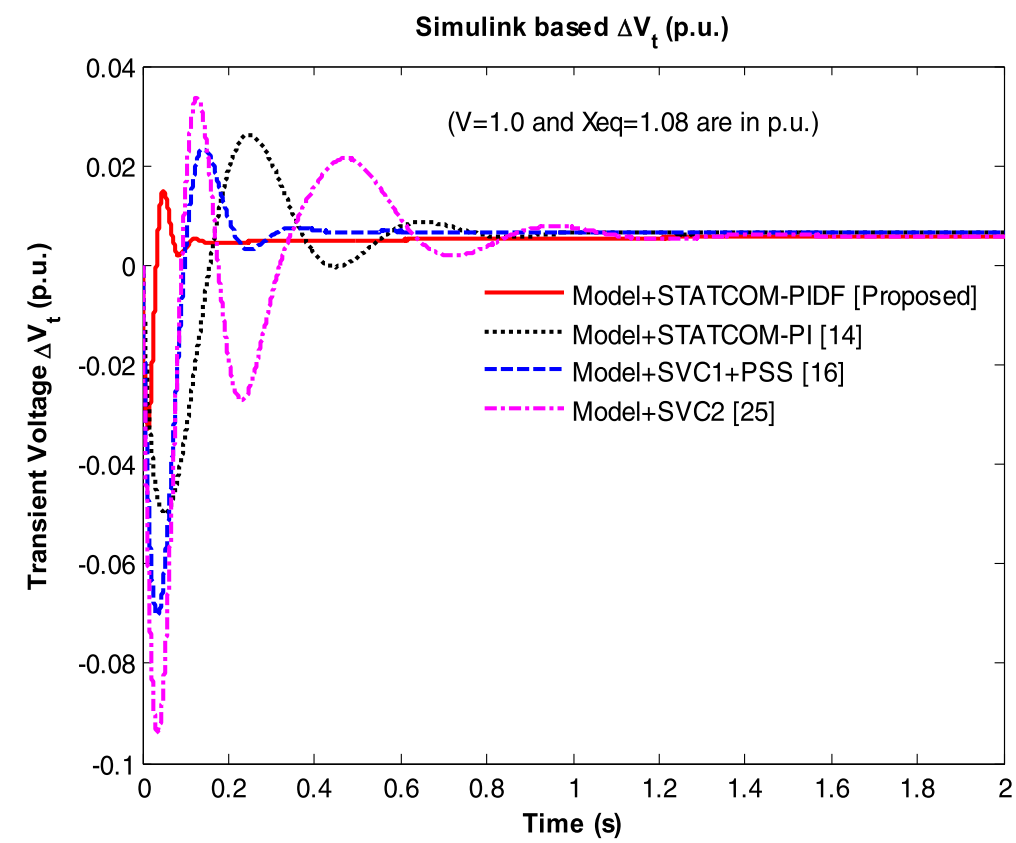

Fig. 9 Comparative study using different controllers with SOS optimization technique 


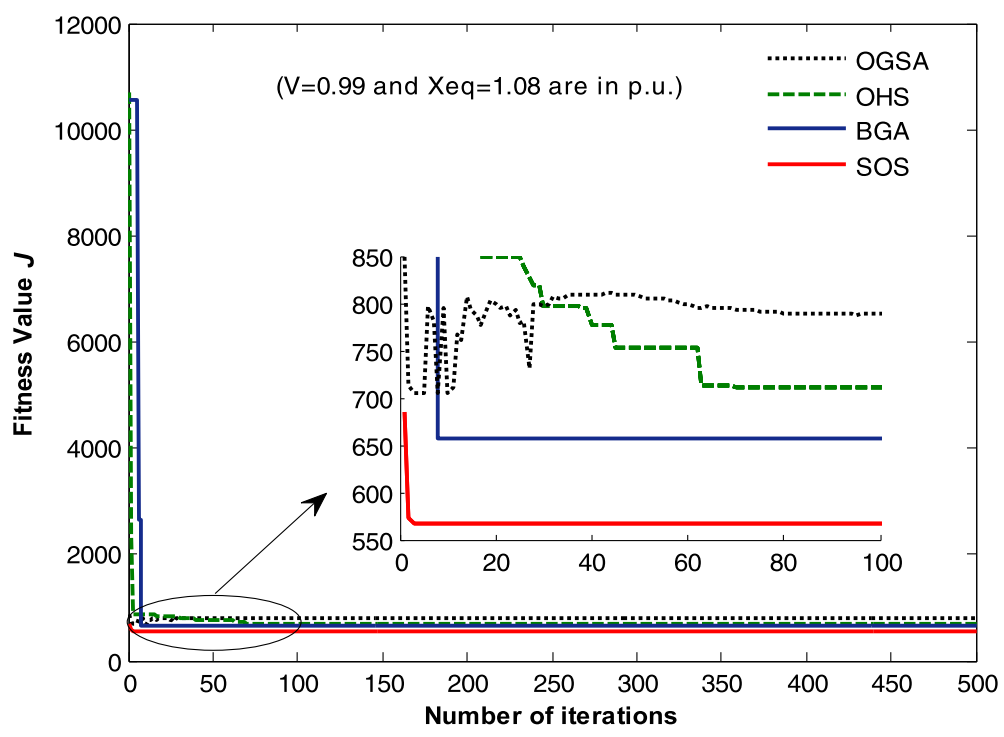

Fig. 10 Comparative convergence profile study among the algorithms

$K_{p}, K_{i}, K_{d}$ Proportional, integral and derivative gain of the PIDF controller, respectively.

$N, T$ Derivative filter coefficients of the PIDF controller. $T_{c}, T_{d}$ Transport lag and phase sequence delay of the STATCOM controller, respectively.

$\Delta \alpha$ Change in phase angle of the STATCOM controller. $K_{A}$ Gain of the exciter.

$K_{V}, T_{V}$ Gain and time constant in energy balance loop, respectively.

$T_{d 0}^{\prime}$ Direct axis open circuit time constant, sec.

$T_{G}$ Inertia time constant.

$T_{A}, T_{R}$ Exciter and transducer time constants, respectively, sec.

$\Delta T_{m}, \Delta T_{e}$ Incremental change in mechanical and electrical torque, respectively, p.u.

$\Delta \omega_{r}, \Delta \delta$ Incremental change in rotor speed and angle, respectively, p.u.

Table 3 Performance indices parameters for different applied algorithms

\begin{tabular}{llllll}
\hline Input conditions & Algorithms & IAE & IATE & ISE & ITSE \\
\hline $0.97,0.4752$ & BGA & 622.9246 & 0.1037 & 6.9749 & 31.2445 \\
& GSA & 360.2317 & 0.0722 & 2.7375 & 15.3301 \\
& SOS & $\mathbf{3 3 3 . 1 1 3 9}$ & $\mathbf{0 . 0 6 2 3}$ & $\mathbf{2 . 6 9 9 5}$ & $\mathbf{1 3 . 2 8 9 3}$ \\
$1.01,0.752$ & BGA & 621.7943 & 0.1035 & 6.9964 & 30.5948 \\
& GSA & 316.2902 & 0.0805 & 3.1219 & 12.2259 \\
& SOS & $\mathbf{2 7 9 . 0 4 8 8}$ & $\mathbf{0 . 0 7 1 0}$ & $\mathbf{2 . 5 7 5 0}$ & $\mathbf{8 . 6 9 4 6}$ \\
$0.97,1.08$ & BGA & 626.5319 & 0.1043 & 7.2372 & 31.0940 \\
& GSA & 298.4069 & 0.0716 & 2.2083 & 12.5188 \\
& SOS & $\mathbf{2 5 2 . 2 3 9 6}$ & $\mathbf{0 . 0 7 0 2}$ & $\mathbf{2 . 1 5 1 8}$ & $\mathbf{7 . 6 3 2 3}$ \\
\hline
\end{tabular}

$X_{d}, X_{d}^{\prime}$ Direct axis reactance of SG under steady and transient state condition, respectively, p.u.

$r_{1}, r_{2}^{\prime}$ Stator and rotor resistance of the IG, respectively, p.u.

$x_{1}, x_{2}^{\prime}$ Stator and rotor reactance of the IG, respectively, p.u.

Xeq Equivalent reactance of the IG, p.u.

$s$ Slip of the IG.

FOD Performance index as Figure of demerit.

$E_{s s}$ Steady state error, p.u.

$M_{p}$ Overshoot, p.u.

$t_{s}, t_{r}$ Settling and rise time, respectively, sec.

rand() Random variable.

\section{Appendix}

8.1 SG, IG, STATCOM-PIDF and load parameters

The terms $K_{1}, K_{2}, K_{3}, K_{4}, K_{5}$ and $T_{G}$ related to the eqs. $(1-3)$ are further described as

$$
\begin{aligned}
& K_{1}=\frac{2 * V * X_{e q}}{\left(R_{I G}^{2}+X_{e q}^{2}\right)} \\
& K_{2}=\frac{V * \cos \delta}{X_{d}^{\prime}} \\
& K_{3}=\frac{(E * \cos \delta-2 * V)}{X_{d}^{\prime}} \\
& K_{4}=\frac{X_{d}^{\prime}}{X_{d}}
\end{aligned}
$$




$$
\begin{aligned}
& K_{5}=\frac{\left(X_{d}^{\prime}-X_{d}\right) * \cos \delta}{X_{d}^{\prime}} \\
& T_{G}=T_{d 0}^{\prime} \frac{X_{d}^{\prime}}{X_{d}}
\end{aligned}
$$

In (16), the denominator terms i.e., $R_{I G}$ and $X_{e q}$ are again related to the other IG parameters and may written as

$$
\begin{aligned}
& R_{I G}=\frac{r_{2}^{\prime}}{s} *(1-s)+\left(r_{1}+r_{2}^{\prime}\right) \\
& X_{e q}=\left(x_{1}+x_{2}^{\prime}\right)
\end{aligned}
$$

The different IG and SG parameters value in (16)-(23) are given as [16].

For IG: $r_{1}=r_{2}^{\prime}=0.19$ p.u., $x_{1}=x_{2}^{\prime}=0.56$ p.u., $s=-3.5 \%$.

For SG: $V=1.0$ p.u., $\delta=17.2483^{0}, T_{d 0}^{\prime}=5.0 \mathrm{~s}, X_{d}=1.0$ p.u., and $X_{d}^{\prime}=0.15$ p.u.

The other considered data of the proposed STAT COM-PIDF based wind-diesel HPSM are as in $[14,16]$.

$P_{I G}=0.6$ p.u. kW, $Q_{I G}=0.291$ p.u. $\mathrm{kVAr}, P_{i n}=0.667$ p.u. $\mathrm{kW}$, power factor in IG $=0.9, \eta=90 \%, P_{S G}=0.4$ p.u. $\mathrm{kW}$, $Q_{S G}=0.2$ p.u. kVAr, $E_{q}=1.12418$ p.u., $E_{q}^{\prime}=0.9804$ p.u., $P_{\text {load }}=1.0$ p.u. kW, $Q_{\text {load }}=0.75$ p.u. kVAr, power factor of load $=0.8, Q_{\text {com }}=0.841$ p.u. $\mathrm{kVAr}$ and $\alpha=53.32^{\circ}$.

\subsection{Simulink model based power system data}

The different constant data used in the simulation of STATCOM - PIDF based wind-diesel HPSM (Fig. 1) are $G_{1}=1.478, G_{2}=3.8347, K_{V}=0.667, T_{V}=0.0007855$, $K_{A}=200, T_{A}=0.05, T_{R}=0.02, H=1.0, D=0.8, \omega_{0}=314$.

\subsection{Different system matrix $[A]$ components}

Different system matrix $[A]$ components are as follow:

$$
\begin{aligned}
& a 0101=-\frac{D}{2 H} ; a 0102=-\frac{K_{11}}{2 H} ; a 0105=-\frac{K_{22}}{2 H} \text {. } \\
& a 0201=\omega_{0} . \\
& a 0303=-\frac{1}{T_{a}} ; a 0304=-\frac{K_{a}}{T_{a}} . \\
& a 0404=-\frac{1}{T_{r}} ; a 0406=\frac{1}{T_{r}} . \\
& a 0503=\frac{E_{2}}{T_{g}} ; a 0505=-\frac{1}{T_{g}} ; a 0506=\frac{E_{1}}{T_{g}} . \\
& a 0605=\frac{K_{1} K_{v}}{T_{v}} ; a 0606=\frac{L}{T_{v}} ; a 0610=\frac{G_{1} K_{v}}{T_{v}} . \\
& a 0706=-m \times Q ; a 0707=-M \times K_{i} \times Q ; a 0708=-M \times Q \text {. } \\
& a 0804=-\frac{M K_{v} K_{1}}{m T_{v}} ; a 0806=-\left(M \times K_{i} \times Q\right)-\frac{M L}{m T_{v}}-\frac{N_{1}}{M} \\
& a 0807=\left(m \times K_{i}^{2} \times Q\right)+\frac{N_{1} K_{i}}{M}+\frac{K_{i}}{m M Q} ; \\
& a 0808=-\left(m \times K_{i} \times Q\right)-\frac{1}{m M Q}-\frac{N_{1}}{M} ; a 0810=-\frac{M K_{v} G_{1}}{m T_{v}} . \\
& a 0908=\frac{1}{T_{c}} ; a 0909=-\frac{1}{T_{c}} . \\
& a 1009=\frac{1}{T_{d}} ; a 1010=-\frac{1}{T_{d}} . \\
& \text { Here, } L=-1-\left(K_{v} \times E_{2}\right)-\left(K_{v} \times G_{2}\right)+\left(K_{v} \times K_{2}\right) \text {; }
\end{aligned}
$$

$$
\begin{aligned}
& m=\frac{T}{N} ; \quad M=\left(m \times K_{p}\right)+K_{d} ; \quad N_{1}=\left(m \times K_{i}\right)+K_{p} ; \\
= & \frac{1}{M-\left(m \times N_{1}\right)}
\end{aligned}
$$

\subsection{Algorithms parameters}

For GSA [25]: jumping rate, $J_{r}=0.3 ; G_{0}=100 ; \tau=20$. $r$ Norm $=2$, $r$ Power $=1$ and $\xi=0.0001$.

For BGA [15]: number of bits $=$ (number of parameters) $\times 8$ (as considered in the present work), mutation probability $=0.001$, crossover rate $=80 \%$.

\section{Acknowledgements \\ The support received from Department of Electrical Engineering, National Institute of Technology, Arunachal Pradesh, India is deeply acknowledged.}

\section{Authors' contributions}

The first author of this article does the whole simulation part and also written the article under the guidance of corresponding author. The corresponding author fully checked the article and made the major changes in it. The first author of this article does the whole simulation part with the help of corresponding author in MATLAB. The model has been developed by the first author and corresponding author with the help of some international reputed journals and mathematical calculation. The mathematical calculation of the total model of each state has been calculated by the first author for the Eigen value analysis to check the stability of the hybrid model. Different optimization techniques are also applied by first author to tune the different controller parameters. By optimal tuning of the controller parameters the reactive power is truly compensated with faster convergence is achieved by first author and corresponding author. The results are also compared among three different algorithms by both the authors. After that the paper is thoroughly checked by both first author and corresponding author and made the major changes in it. The author(s) read and approved the final manuscript.

\section{Authors' information}

P. K. Guchhait (1991-) was born at Paschim Medinipur, West Bengal, India. He received his B. Sc (Physics Hons.) degree from R.K. Mission Vivekananda Centenary College (under W.B.S.U) at 2011. Thereafter, he received his B. Tech and M. Tech degree from University of Calcutta, India in 2014 and 2016, respectively. Now, he is pursuing Ph. D from National Institute of Technology, Arunachal Pradesh, India.

A. Banerjee (1986-) was born at Burnpur, Burdwan, West Bengal, India. He received his $B$. Tech degree in electrical engineering from Asansol Engineering College, Asansol, Burdwan, India and M. Tech. in Power System from Dr. B. C. Roy Engineering College, Durgapur, Burdwan, India, respectively. He has done his Ph.D. degree from Indian Institute of Technology (Indian School of Mines) Dhanbad, Jharkhand, India. Previously, he was working in the capacity of assistant professor in the department of electrical engineering, Asansol Engineering College, Asansol, West-Bengal, India. Currently, he is assistant professor in National Institute of Technology, Arunachal Pradesh, Yupia, India. His research interest includes reactive power control, distributed generation, load tracking. He will be available at abhik_banerjee@rediffmail.com, abhik@nitap.ac.in.

\section{Funding}

This research work has not been received any kind of fund from any sources.

\section{Availability of data and materials}

No data has been taken from any sources.

\section{Competing interests}

The authors declare that they have no competing interests.

Received: 5 November 2019 Accepted: 22 April 2020

Published online: 21 May 2020

References

1. Kundur, P. (1994). Power system stability and control. New York: Mc Graw-Hill. 
2. Kundur, P., Rogers, G., Wong, D. Y., Wang, L., \& Lauby, M. G. (1990). A comprehensive computer program package for small signal stability of power systems. IEEE Trans Power Syst, 5(4), 1076-1083.

3. Avramovic, B., \& Fink, L. H. (1995). Energy management systems and control of FACTS. Int J Electr Power Energy Syst, 17(3), 195-198.

4. Eker, I., \& Johnson, M. A. (1995). Power system stability control with robust multi-loop automatic voltage regulators. IFAC Proceedings Volumes, 28(10), 185-190.

5. Guha, D., Roy, P. K., \& Banerjee, S. (2018). Optimal tuning of 3 degree-offreedom proportional integral derivative controller for hybrid distributed power system using dragonfly algorithm. Comput Electric Eng, 72, 137-153.

6. Pandey, S. K., Kishor, N., \& Mohanty, S. R. (2014). Frequency regulation in hybrid power system using iterative proportional-integral-derivative $H_{\infty}$ controller. Electr Power Components Syst, 42(2), 132-148.

7. Singh, V. P., Mohanty, S. R., Kishor, N., \& Ray, P. K. (2013). Robust H-infinity load frequency control in hybrid distributed generation system. Int J Electr Power Energy Syst, 46, 294-305.

8. Borhanazad, H., Mekhilef, S., Ganapathy, V. G., Modiri-Delshad, M., \& Mirtaheri, A. (2014). Optimization of micro-grid system using MOPSO. Renew Energy, 71, 295-306.

9. Bansal, R.C., \&Bhatti, T.S. (2008). Small signal analysis of isolated hybrid power systems: reactive power and frequency control analysis. Alpha science, (pp 1-240).

10. Banerjee, A., Guchhait, P. K., Mukherjee, V., \& Ghosal, S. P. (2018). Seeker optimized SVC-PID controller for reactive power control of an isolated hybrid power system. Energy Systems, 10(4), 985-1015.

11. Hingorani, N. G., Gyugyi, L., \& El-Hawary, M. (2000). Understanding FACTS: Concepts and technology of flexible AC transmission systems (Vol. 1). New York: IEEE press.

12. Sharma, P., \& Bhatti, T. S. (2013). Performance investigation of isolated winddiesel hybrid power systems with WECS having PMIG. IEEE Trans Ind Electron, 60(4), 1630-1637.

13. Mohanty, A., Viswavandya, M., Ray, P. K., \& Patra, S. (2014). Stability analysis and reactive power compensation issue in a microgrid with a DFIG based WECS. Int J Electr Power Energy Syst, 62, 753-762.

14. Saxena, N. K., \& Kumar, A. (2016). Reactive power control in decentralized hybrid power system with STATCOM using GA, ANN and ANFIS methods. Int J Electr Power Energy Syst, 83, 175-187.

15. Aidoo, I. K., Sharma, P., \& Hoff, B. (2016). Optimal controller's designs for automatic reactive power control in an isolated wind-diesel hybrid power system. Int J Electr Power Energy Syst, 81, 387-404.

16. Banerjee, A., Mukherjee, V., \& Ghoshal, S. P. (2013). Modeling and seeker optimization based simulation for intelligent reactive power control of an isolated hybrid power system. Swarm Evolut Comput, 13, 85-100.

17. Cheng, M. Y., \& Prayogo, D. (2014). Symbiotic organisms search: A new metaheuristic optimization algorithm. Comput Struct, 139, 98-112.

18. Shaw, B., Banerjee, A., Ghoshal, S. P., \& Mukherjee, V. (2011). Comparative seeker and bio-inspired fuzzy logic controllers for power system stabilizers. Int J Electrical Power Energy Syst, 33, 1728-1738.

19. Gaing, Z. L. (2004). A particle swarm optimization approach for optimum design of PID controller in AVR system. IEEE Transact Energy Conversions, 19, 384-391.

20. Banerjee, A., Mukherjee, V., \& Ghoshal, S. P. (2014). Intelligent fuzzy-based reactive power compensation of an isolated hybrid power system. Int Electr Power Energy Syst, 57, 164-177.

21. Sivanandam, S.N., \& Deepa, S.N. (2008). Genetic algorithm optimization problems. In Introduction to Genetic Algorithms. Springer, Berlin, Heidelberg, pp 165-209.

22. Ali, E. S., Abd Elazim, S. M. \& Abdelaziz, A. Y. (2017). Ant lion optimization algorithm for optimal location and sizing of renewable distributed generations. Renew Energy, 101, 1311-1324.

23. Verma, S., Saha, S., \& Mukherjee, V. (2016). A novel symbiotic organisms search algorithm for congestion management in deregulated environment. J Exp Theor Artificial Intelligence, 29(1), 56-79.

24. Banerjee, A., Mukherjee, V., \& Ghoshal, S. P. (2014). An opposition-based harmony search algorithm for engineering optimization problems. Ain Shams Engineering Journal, 5(1), 85-101.

25. Rashedi, E., Nezamabadi-pour, H., \& Saryazdi, S. (2009). GSA: A gravitational search algorithm. Inf Sci, 179(13), 2232-2248.

\section{Submit your manuscript to a SpringerOpen ${ }^{\circ}$ journal and benefit from:}

- Convenient online submission

- Rigorous peer review

- Open access: articles freely available online

- High visibility within the field

- Retaining the copyright to your article

Submit your next manuscript at $\boldsymbol{\nabla}$ springeropen.com 